\title{
Multicomponent Binders with Organic Mineral Additive Based on Volcanic Ash
}

\author{
Murtazaev S-A.Y. \\ Department of materials science and engineering \\ Kh. Ibragimov Complex Institute of the Russian Academy \\ of Sciences \\ Department of technical sciences \\ Academy of science of the Chechen Republic \\ Grozny State Petroleum Technical University \\ named M.D. Millionschikov \\ Grozny, Russia \\ s.murtazaev@mail.ru \\ Bisultanov R.G. \\ Building faculty \\ Grozny State Petroleum Technical University \\ named M.D. Millionschikov \\ Grozny, Russia \\ ramazan_bisultanov@mail.ru
}

\author{
Salamanova M.Sh. \\ Department of materials science and engineering \\ Kh. Ibragimov Complex Institute of the Russian Academy \\ of Sciences \\ Building faculty \\ Grozny State Petroleum Technical University \\ named M.D. Millionschikov \\ Grozny, Russia \\ madina_salamanova@mail.ru
}

\author{
Abukhanov A.Z. \\ Building faculty \\ Grozny State Petroleum Technical University \\ named M.D. Millionschikov \\ Grozny, Russia \\ abuhanov54@mail.ru
}

\author{
Alaskhanov A.Kh. \\ Building faculty \\ Grozny State Petroleum Technical University \\ named M.D. Millionschikov \\ Grozny, Russia \\ ooo-uspekh@rambler.ru
}

\begin{abstract}
This paper is devoted to the development of multicomponent binders with the usage of finely dispersed mineral additives. In the course of the research it was found that mineral components of binders, combined with chemical additives favorably affect the process of structuring of cement stone, control the beginning and end of setting, regulate the kinetics of strength and setting, durability and operational reliability of concrete.
\end{abstract}

Keywords-multicomponent binders, organic mineral additives, vibroactivation, portland cement clinker, volcanic ash, superplasticizer, ultrasound speed, structure

\section{INTRODUCTION}

The main component of concrete is cement. Varying the components of cement binder, using finely dispersed mineral additives of various nature in its composition, it is possible to obtain composite materials with variable properties. Binders obtained in such a way are called multicomponent.

Numerous studies [1-3] have proved that mineral components of binders have a positive effect on the process of structure formation of cement stone. Moreover they control the beginning and end of setting, regulate the kinetics of strength and setting, shrinkage, corrosion resistance, durability and operational reliability of concrete.

The use of multicomponent binders for the production of construction compositions is a solution to one of the most important problems of the cement industry. On the one hand, the problem of consumption of one the most expensive components of Portland cement-clinker will be solved, and, on the other hand, it will improve the environmental situation by reducing emissions of dust and CO. Since it is known that a high concentration of dust in emissions is present at almost all stages of cement preparation.

In addition, it should be admitted that the use of multicomponent binders in modern monolithic and precastmonolithic construction is not only desirable, but also a necessary condition and standard for obtaining high-quality and high-tech concrete and reinforced concrete products [2, 3].

It was found that mineral components added to the composition of both a binder and a concrete, after preliminary mechanical activation, to a certain degree of dispersion make it possible to increase the design class of concrete and produce products with certain properties at lower cost significantly reducing the consumption of Portland cement. In addition, there is a positive effect on the degree of the hydration of clinker minerals and the formation of an improved concrete microstructure [3].

\section{METHODS AND MATERIALS}

Mineral components used to obtain multi-component binders 
can be divided into two large groups:

- mineral additives with hydraulic properties;

- additives - fillers that improve the grain composition and structure of hardened cement stone and concrete.

In accordance with State Industry Standard 31108, granulated slag, fuel ashes, silica fume, burnt clay, burnt shale, caliche, flask, silica clay, limestone, quartz sand $[6,7]$ are used as mineral components - the main components of cement. Various mineral additives can be used as auxiliary components of cement, which will not significantly increase the water demand of cement, as well as reduce the durability of concrete.

Due to high specific surface, finely dispersed active mineral additives have a positive effect on the physicochemical parameters in the contact zone of phase separation. With the formation of a condensation-crystallization structure, the active centers are formed in the zone of contact of cement with fillers, contributing to the accelerated nucleation of new growth crystals, an increase in their number, a certain orientation of the new phase relative to filler particles, which causes an increase in the adhesion of a filler to a binder [1, 2, 8-10].

Thus, any finely dispersed mineral substance used in the recipe of a multicomponent binder is included in the structure of crystalline skeleton and is an important link within the setting hydration system.

Natural rocks of volcanic origin have long been widely used as mineral finely dispersed fillers for the production of multicomponent binders and organic-mineral additives, as they are characterized by high chemical activity.

Volcanic ash was used as far back as 2000 years ago in Ancient Rome, when builders made cement for offshore structures, mixing lime and volcanic rocks. This compound was placed in wooden forms, where sea water was added, which instantly caused a high-temperature chemical lime slaking reaction. As a result the strongest cement blocks were created, the main bonding agent in which was not a compound calciumsilicate hydrate (C-S-H), but calcium-aluminum-silicate hydrate (C-A-S-H) compound.

Scientists have described an extremely rare mineral aluminum tobermorite - one of calcium hydrosilicates (formula: $\left.\mathrm{Al} \cdot \mathrm{Ca}_{5} \cdot \mathrm{Si}_{6} \mathrm{O}_{16} \cdot(\mathrm{OH})_{2} \cdot 4 \mathrm{H}_{2} \mathrm{O}\right)$, which is formed during the chemical reaction of cement with sea water. Roman concrete did not crumble despite an aggressive marine environment. This concrete is considered to be one of the most durable building materials on our planet [3.7].

In ancient Armenia, volcanic ash and tuff were used as raw material for solid brick and blocks, which have long been popular among residents. The strength of bricks from the volcanic ash is analogous to the performance of the most advanced modern bricks. Scientists from Argentina proposed a whole range of innovative technologies that allow making bricks from ash without significant expenses. Japanese architects designed the building of bricks, which are compressed with the addition of the ashes of the ancient volcano Sakurajima in Japan.
Japanese scientists succeeded to establish that the addition of volcanic ash to the mass for building bricks increases the thermal conductivity of a material, improves moisture resistance and increases its strength [4].

Volcanic plaster was developed in Japan and it presents the main component of volcanic ash. This plaster adsorbs completely unpleasant odors, harmful and toxic substances. A healthy atmosphere on the walls of a house, covered with this material, is guaranteed. Such plaster retains a constant, comfortable level of humidity for a person. It absorbs excess moisture in a damp room, and keeps necessary level of humidity in a dry room. Moreover, this material does not burn.

\section{RESULTS}

In countries where there are large reserves of volcanic ash, the revival of this technology can be economically justified. In Russia there are volcanic rocks in Kabardino-Balkaria and in Kamchatka, and they present a unique raw material for the construction industry.

The chemical analysis of volcanic ash particles of Kabardino-Balkaria is represented by the following oxides, \% by mass: $\mathrm{MgO}=0.2 ; \mathrm{Al}_{2} \mathrm{O}_{3}=13.6 ; \mathrm{SiO}_{2}=73.7 ; \mathrm{K}_{2} \mathrm{O}=6.0$; $\mathrm{CaO}=1.8 ; \mathrm{Fe}_{2} \mathrm{O}_{3}=1.52 ; \mathrm{Na}_{2} \mathrm{O}=2.85 ; \mathrm{CuO}=0.4$. The microstructure of volcanic ash particles was studied using a scanning electron microscope of the Quanta 200 3D system. Figure 1 shows micrographs of volcanic ash particles, image magnification is 5000 .

The traditional technology of preparation of organic-mineral additives (OMA) for the production of multicomponent binders is based on mixing pre-crushed mineral component with water solutions of surfactants and further drying at the temperature of $150-170{ }^{\circ} \mathrm{C}$ to a residual moisture content of a material equal to $1-1.5 \%$. The resulting powdered additive is easily molded and able to briquetting. In this form, OMAs are easily stored, transported, dosed and injected into concrete compound.
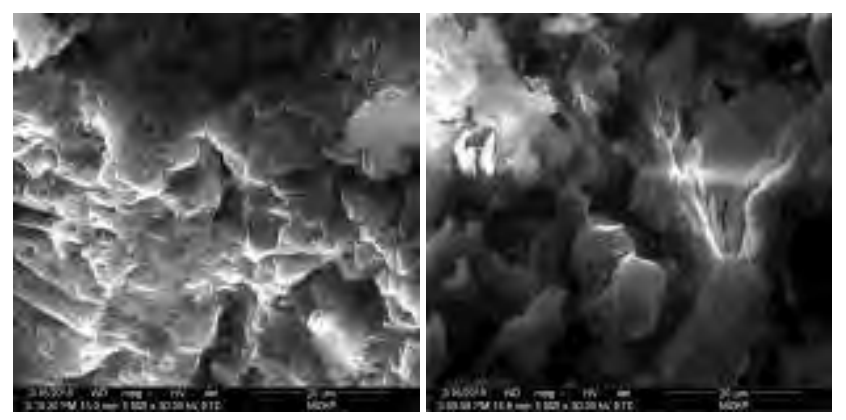

Fig. 1. Micrographs of volcanic ash particles of Kabardino-Balkaria.

This research proposes the technology for the preparation of OMA using a pre-crushed mineral component with its further grinding together with powdered surfactant, to the optimum specific surface, which is determined by laboratory. Thereby, the basic principle of mechanochemical activation of the surface of mineral filler is realized, contributing to the increase in its surface energy (Figure 2). 


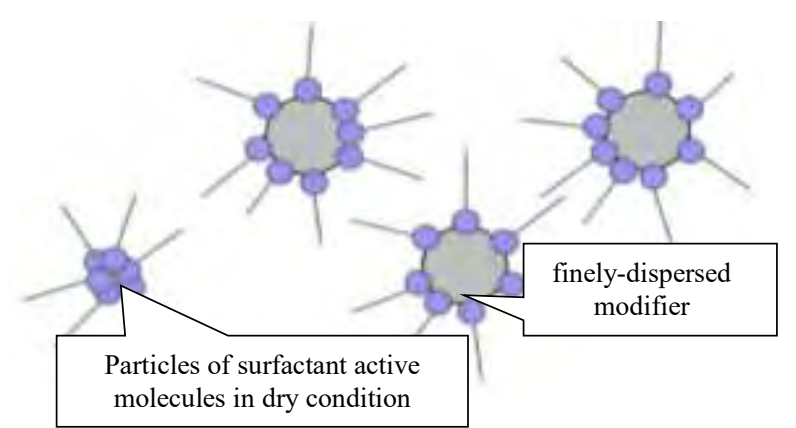

Fig. 2. The structure of organic mineral additives.

Mechanical activation of material in geological and technological processes contributes to a number of physicochemical phenomena:

- the violation of crystalline grid of rock-forming minerals;

- the formation of micro cracks, defects and point dislocation centers;

- the destruction of chemical bonds.

All these phenomena contribute to the formation of a large stock of "excess" energy. And, as a result, the particles with sizes corresponding to the parameters of simple crystalline grid appear. Continuing dispersion may lead to the destruction of crystalline bonds, thereby thermodynamic characteristics of minerals change accordingly, which will entail the increase in its reactivity. The presence of surfactant active molecules prevents the convergence of fine particles of filler and stabilizes its properties, and, therefore, becomes a carrier of a surfactant.

In order to test this working hypothesis, the experiment was carried out with the use of plasticizer with various chemical compositions and mechanism of activation of plasticizing additives:

- Polyplast SP-1 - superplasticizer, which is a compound of sodium salts of polymethylene naphthalene sulfonic acids of various molecular weights;

- LST - Lignosulphonate technical superplasticizer in the form of powder;

- REOMAX PC 3904 P - hyperplasticizer based on modified and stabilized polycarboxylate copolymers in form of powder.

Superplasticizers Polyplast SP-1 and LST are famous additives; their mechanism of action is based on the effect of electrostatic repulsion of cement particles and mineral additive and stabilization of suspension. The effect of the plasticizer REOMAX PC 3904 P is based on the combination of electrostatic and spatial effect, which is achieved with the help of side hydrophobic polyether chains of polycarboxylate ether molecule.

The plasticizers mentioned above are in the compound of organic mineral additives, prepared with the help of different ways (Table 1). The recipe of OMA is selected experimentally, providing the necessary conditions for the effective synthesis of a multicomponent binder. The content of volcanic ash is $20 \%$ by weight of cement, while the concentration of plasticizers in the binder varies from 0.2 to $1.5 \%$ by weight of cement, which corresponds to the existing recommendations for dosing in $\%$ by weight of cement: Polyplast SP-1 - from 0.2 up to 1.0; LST from 0.2 to 1.5 ; REOMAX PC $3904 \mathrm{P}$ - from 0.5 to 1.0 .
TABLE I. THE COMPOSITION AND PREPARATION OF OMA

\begin{tabular}{|c|c|c|c|}
\hline \multirow{2}{*}{ Compound code } & \multicolumn{2}{|c|}{ The composition of OMA, \% } & \multirow{2}{*}{$\begin{array}{c}\text { The way of } \\
\text { preparation }\end{array}$} \\
\cline { 2 - 3 } & Volcanic ash & $\boldsymbol{S P}$ & Mixed grinding in \\
vibration mill
\end{tabular}

A mixed grinding of mineral and organic components in a vibration mill for 1 hour was carried out with the aim of mechanochemical activation of additives of both types, as well as enhancing the adsorption process of plasticizers on the surface of volcanic ash, up to chemisorption.

Prepared organic additives were mixed together with cement in the ratio of $21: 79 \%$. A paste of normal thickness was prepared from the obtained compounds and beams of $40 \times 40 \times 160 \mathrm{~mm}$ were created in order to test the strength characteristics. The studies were carried out in comparison with CEM I $42.5 \mathrm{~N}$ of Chiri Yurtovsky cement plant, as well as compositions containing mineral and organic additives separately. The test results of a multicomponent binder are shown in Table 2 and in Figure 3.

TABLE II. THE TEST RESULTS OF MULTICOMPONENT BINDERS

\begin{tabular}{|c|c|c|c|c|}
\hline \multicolumn{5}{|c|}{ WITH OMA } \\
\hline  & A type of a binder & $\begin{array}{c}\text { Specific } \\
\text { surface, } \\
\mathbf{m}^{2} / \mathbf{k g}\end{array}$ & $\begin{array}{c}\text { Normal } \\
\text { consistency, } \\
\%\end{array}$ & $\begin{array}{c}\text { Real } \\
\text { density, } \\
\text { g/sm }\end{array}$ \\
\hline 1 & CEM I 42.5H & 330 & 25.0 & 3.10 \\
\hline \multicolumn{5}{|c|}{ OMA vibroactivation 60 minutes } \\
\hline 2 & $\begin{array}{c}\text { Cement }+ \text { volcanic } \\
\text { ash }\end{array}$ & 994 & 28.7 & 2.94 \\
\hline 3 & $\begin{array}{c}\text { Cement }+ \text { (volcanic } \\
\text { ash }+ \text { Polyplast })\end{array}$ & 1082 & 22.8 & 2.84 \\
\hline 4 & $\begin{array}{c}\text { Cement + (volcanic } \\
\text { ash +LST) }\end{array}$ & 1010 & 24.2 & 2.81 \\
\hline 5 & $\begin{array}{c}\text { Cement + (volcanic } \\
\text { ash + REOMAX) }\end{array}$ & 1140 & 20.1 & 2.88 \\
\hline
\end{tabular}

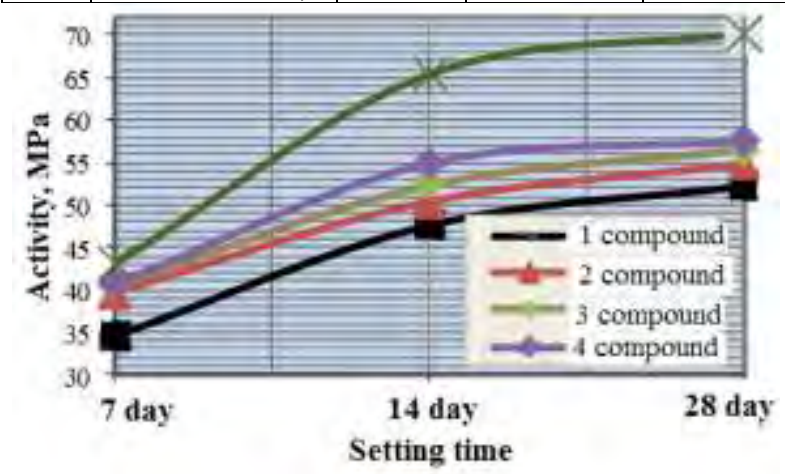

Fig. 3. The diagram of the dependence of multicomponent binders on time of setting.

All studied organic mineral additives showed a waterreducing effect, since the decrease in normal density of multicomponent binders was noted. Multicomponent binder cement + (volcanic ash + REOMAX) has the best water reducing effect and reduces normal thickness up to $20 \%$.

The use of organic mineral additives also leads to the increase in strength, both in the early stages of setting and at the age of 28 days. The most effective should be considered OMA "volcanic ash + REOMAX", prepared by joint grinding and mechanochemical activation in a vibration mill of volcanic ash 
and hyperplasticizer REOMAX RS 3904 R. Mixed grinding leads to the internal penetration of hyperplasticizer into the surface of volcanic particles ash, thereby enhancing the process of its monomolecular adsorption, as well as contributing to the fine grinding and activation of ash.

Thus, the compositions of a multicomponent binder based on volcanic ash with an activity of $70 \mathrm{MPa}$ were developed; the effectiveness of using a REOMAX PC 3904 P hyperplasticizer based on polycarboxylate copolymers in the form of powder was proven.

Next, the authors investigated the duration of the formation of a structure of cement stone at the early stage of setting, which was determined according to State Industrial Standard 310.3-81 by the ultrasonic method and the method of changing the temperature of a compound. The results of the determination of the formation period of cement stone structure (Table 3, Figure $4 \mathrm{a}, \mathrm{b})$ showed that when using volcanic ash as a mineral additive, the setting time was practically unchanged, but the use of the proposed organic-mineral additives based on volcanic ash in combination with chemical additives significantly slow down the period of formation of the structure for several hours.

TABLE III. THE DETERMINATION OF FORMATION PERIOD OF STRUCTURE BY SETTING TIME

\begin{tabular}{|c|c|c|c|c|}
\hline \multirow{3}{*}{ 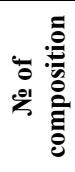 } & \multirow{3}{*}{ A type of a binder } & \multicolumn{3}{|c|}{ Setting time, hours-minutes } \\
\hline & & \multirow{2}{*}{$\begin{array}{c}\begin{array}{c}\text { Ultrasonic } \\
\text { method }\end{array} \\
\text { The } \\
\text { beginning }\end{array}$} & \multicolumn{2}{|c|}{$\begin{array}{c}\text { According to the } \\
\text { change of temperature }\end{array}$} \\
\hline & & & $\begin{array}{c}\text { The } \\
\text { beginning }\end{array}$ & The end \\
\hline \multicolumn{5}{|c|}{ OMA vibroactivation 60 minutes } \\
\hline 1 & Cement + volcanic ash & $2: 15$ & $2: 23$ & $7: 22$ \\
\hline 2 & $\begin{array}{c}\text { Cement }+ \text { (volcanic ash }+ \\
\text { Polyplast })\end{array}$ & 3:09 & $3: 17$ & $8: 47$ \\
\hline 3 & $\begin{array}{c}\text { Cement }+(\text { volcanic ash } \\
+ \text { LST })\end{array}$ & $4: 26$ & 4:06 & $8: 50$ \\
\hline 4 & $\begin{array}{c}\text { Cement }+(\text { volcanic ash }+ \\
\text { REOMAX) }\end{array}$ & $3: 21$ & $3: 30$ & $9: 23$ \\
\hline
\end{tabular}
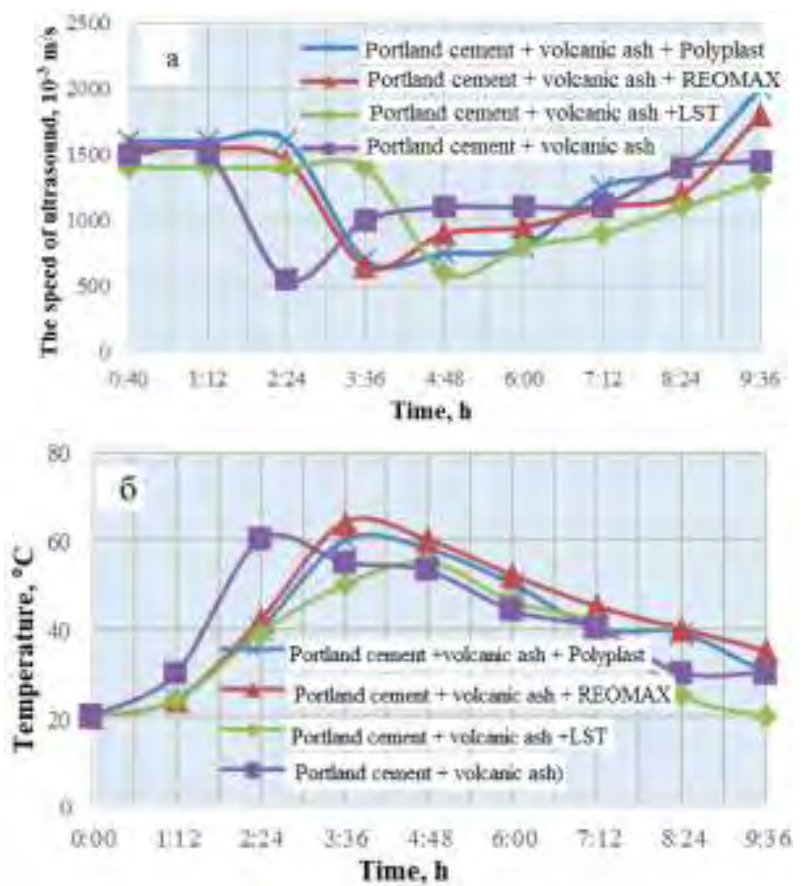

Fig. 4. The influence of OMA type on the speed of ultrasound (a) and the dynamic of temperature change (b)
The diagram of Figure $4 a, b$ shows a sharp decrease in the speed of ultrasound and a sharp increase in hydration temperature, these moments correspond to the beginning of the structure formation period, while it should be noted that the use of organic mineral additives slows down the structure formation processes in the initial period, but later on reactions of formation of secondary hydrosilicates and calcium hydroaluminates proceed faster.

\section{CONCLUSION}

Thus, the recipes of multicomponent binders based on organic mineral additives were developed, contributing to the increase in strength, both at the early stages of setting and at the age of 28 days. Used multicomponent binders in the production of construction compositions will save the most expensive component of concrete - Portland cement clinker.

The results of the research confirmed that the use of multicomponent binders in modern monolithic and precastmonolithic construction is not only desirable, but also a necessary condition and standard for obtaining high-quality and high-tech concrete and reinforced concrete products

\section{References}

[1] S.A.Y. Murtazaev, M.Sh. Salamanova, "Prospects for the use of thermally activated raw materials of aluminosilicate nature," Privolzhsky Scientific Journal, vol. 46, No 2, pp. 65-70, 2018.

[2] V.V. Nelubova, P.K. Hou, and V.V. Strokova, "Complex study of binder properties," AER-Advances in Engineering Research, vol. 133, pp. 543$548,2017$.

[3] A. Bentur, "Cement materials - nine millennia and a new century: past, present and future," Journ. of materials in civil eng., No 1, pp. 2-22, 2002.

[4] J.C. Walraven, "Concrete a new century," Proc. of the 1st FIB Congr., Tokyo, pp. 11-22, 2002

[5] V.T. Erofeev, A.D. Bogatov, S.N. Bogatova [etc.], "Bioresistant building composites on the glass wastes," Biosciences Biotechnology Research Asia, vol. 12, No 1, pp. 661-669, 2015.

[6] S.A.Y. Murtazaev, M.Sh. Salamanova, R.G. Bisultanov, "High-quality modified concretes using a binder based on the reactive active mineral component," Building materials, No 8, pp. 74-80, 2016

[7] T.A. Khegev, "Experimental and theoretical studies of the flame retardant properties of gypsum vermiculite concrete with volcanic rock additives," Problems of rational use of natural and man-made raw materials from the Barents region in the technology of building and technical materials: materials of the 4th International Conference. Arkhangelsk, pp. 153-156, 2010.

[8] D.O. Bondarenko, N.I. Bondarenko, V.S. Bessmertnyi [etc.], "Plasmachemical modification of concrete," Advances in Engineering Research (AER), vol. 157, pp. 105-110, 2018.

[9] V.V. Strokova, Y.V. Sokolova, A.M. Ayzenshtadt [etc.], "Energy characteristics of finely dispersed rock systems," IOP Conference Series: Materials Science and Engineering, vol. 365, 032036, 2018.

[10] V.V. Strokova, Y.V. Sokolova, A.M. Ayzenshtadt [etc.], "Surface tension determination in glyoxal-dispersed system," Journal of Physics: Conference Series, vol. 1038, 1 (1), 012141, 2018. 